\title{
Current situation of congenital heart diseases in two public hospitals in the state of Jalisco
}

\section{Situación real de las cardiopatías congénitas en dos hospitales públicos del estado de Jalisco}

\author{
Rocío A. Peña-Juárez ${ }^{*}$ and Miguel A. Medina-Andrade ${ }^{2}$ \\ ${ }^{1}$ Department of Pediatric Cardiology, Hospital General de Occidente; ${ }^{2}$ Department of Pediatric Cardiovascular Surgery, Hospital Civil Fray Antonio \\ Alcalde. Zapopan, Jalisco, Mexico
}

\begin{abstract}
Introduction: Congenital heart disease represents a public health issue worldwide. Objective: To know the number of patients with heart disease treated in two public hospitals of the State of Jalisco, as well as the mortality and resources available to participating hospitals for the care of these patients in the period from 2015 to 2018; the information was requested to the National Transparency Platform, and the database of pediatric cardiology services and pediatric cardiovascular surgery of the participating hospitals were also reviewed. Results: The second level hospital has human resources, but not the material to attend to these patients; so it is not possible to offer any type of palliative or corrective treatment. A total of 624 patients were evaluated, of which $92.2 \%$ corresponded to non-critical heart disease; overall mortality was $12 \%$ but in critical heart disease it was $79.5 \%$. The third level hospital has human and material resources to care for these patients. During the study period, 289 operations were performed and the overall mortality was $20.4 \%$. Conclusion: Congenital heart disease in the State of Jalisco is an important cause of mortality, with a high incidence and a very limited resolution capacity since the health services in the State of Jalisco for the care of these patients are insufficient and inadequate. It is essential to strengthen the health system for the care for these patients.
\end{abstract}

Key words: Congenital heart defect. Hospital. Pediatric. Mortality.

\section{Resumen}

Introducción: Las cardiopatías congénitas representan un problema de salud pública a nivel mundial. Objetivo: Conocer la cantidad de pacientes cardiópatas atendidos en dos hospitales públicos del estado de Jalisco, así como la mortalidad y los recursos con que cuentan los hospitales participantes para la atención de estos pacientes en el período del 2015 al 2018. Se solicitó la información a la Plataforma Nacional de Transparencia y además se revisaron las bases de datos de los servicios de cardiología pediátrica y cirugía cardiovascular pediátrica de los hospitales participantes. Resultados: El hospital de segundo nivel cuenta con los recursos humanos, pero no con el material para atender a estos pacientes, por lo que no es posible ofrecer ningún tipo de tratamiento paliativo o correctivo (sólo se cierran algunos conductos arteriosos en la etapa

\section{Correspondence:}

*Rocío A. Peña-Juárez

E-mail: alepejz@gmail.com
Available online: 04-09-2020

Date of reception: 08-07-2019

Date of acceptance: 21-10-2019

DOI: 10.24875/ACME.M20000105
Arch Cardiol Mex (Eng). 2020;90(2):124-129

www.archivoscardiologia.com

2604-7063 / @ 2019 Instituto Nacional de Cardiología Ignacio Chávez. Published by Permanyer. This is an open access article under the CC BY-NC-ND license (http://creativecommons.org/licenses/by-nc-nd/4.0/). 
neonatal). Se valoró a un total de 624 pacientes, de los cuales el 92.2\% correspondió a cardiopatías no críticas; la mortalidad global fue del $12 \%$ pero en las cardiopatías críticas fue del 79.5\%. El hospital de tercer nivel cuenta con recursos humanos y material para atender a estos pacientes; en el período de estudio se realizaron 289 operaciones y la mortalidad global fue del 20.4\%. Conclusión: Las cardiopatías congénitas en el estado de Jalisco son una causa importante de mortalidad, con una incidencia elevada y una capacidad de resolución sumamente limitada, ya que los servicios de salud de Jalisco para la atención de estos pacientes son insuficientes e inadecuados. Es esencial fortalecer el sistema de salud para atender a estos pacientes.

Palabras clave: Cardiopatía congénita. Hospital. Pediatría. Mortalidad.

\section{Introduction}

Congenital heart disease (CHD) is defined as a serious structural abnormality of the heart or large intrathoracic vessels that cause a real or potential repercussion'. These conditions represent the most common form of serious birth defects ${ }^{2}$. Overall, of the 130 million neonates that are born around the world every year, more than 1 million are regarded as doing it with any CHD, which constitutes a global public health problem. The incidence of severe CHD is close to $2.5-3 / 1000$ births $^{3}$. In 2000, a global prevalence of $11.9 / 1000$ children was calculated $^{4}$. In this country, the real prevalence of $\mathrm{CHD}$ is unknown; available information is based on 2015 mortality rates. CHDs are the second cause of mortality in children younger than 1 year and, in the period from 1 to 14 years, CHD climbed from the third to the second cause, displacing childhood cancer.6. Often, CHD mortality data can be interpreted within the context of medical and surgical care availability, and mortality data therefore reflect natural evolution of the disease ${ }^{7}$ in countries with limited access to heart surgery procedures. The need for resources to care for these patients is highly important; according to the proposal by Calderón et al., in $2010^{5}$, around 25 cardiac surgery centers were required for CHD in Mexico. In the state of Jalisco, there are three large public hospital centers that serve the most vulnerable population; however, only one has the human and material resources to care for these patients, which is notoriously insufficient. In this sense, it is necessary to know the epidemiological characteristics of CHD in this state, to determine the necessary number of pediatric cardiologists, cardiovascular surgeons, pediatric intensivists, health-care services, perfusionists, and other resources to adequately address the care of these patients. Consequently, the magnitude and distribution of heart disease in Jalisco must be known to obtain data that help to plan actions, offer assistance to affected patients and reduce its effects on mortality. Of note, there are no state-level population-based or epidemiological studies that allow an approach to the knowledge of the magnitude and distribution by type of heart disease; therefore, one of the purposes of this study was to determine the frequency of heart diseases attended to in two of the public hospitals of the state of Jalisco in the 2015-2018 period, in addition to knowing the mortality of these individuals in said institutions and the resources the hospitals have for the care of these patients.

Beyond the usefulness of this work, its main purpose is to alert about the importance of CHD in the state of Jalisco and, indirectly, in many parts of the country, and to describe the reality in this field; in addition, it is necessary to promote the establishment of actions to provide timely and quality care for patients with heart diseases in this state.

\section{Materials and methods}

A descriptive, prospective, and multicenter study was conducted, endorsed by the ethics committee of the General Hospital of the West; a search was carried out in the pediatric cardiology and pediatric cardiovascular surgery departments databases of the participating hospitals, and information was also requested to the National Transparency Platform, with file numbers $04151419,04151319,04151619$, and 04151519 , for 20152018 period, with regard to mortality from congenital heart defects in children younger than 5 years, the number of patients with heart disease cared for within said period and the human and material resources available for the care of heart disease at General Hospital of the West of the Jalisco Ministry of Health (secondary care hospital) and Outpatient Department Civil Hospital of Guadalajara Fray Antonio Alcalde (tertiary care hospital). Descriptive analysis was carried out for patient demographic and clinical characteristics, and highest and lowest values and percentages were measured for categorical variables. All statistical tests were carried out with the IBM-SPSS software, version 24 (SPSS, Chicago, IL, USA). 
Table 1. Data obtained via the National Transparency Platform

\begin{tabular}{|c|c|c|c|}
\hline Hospital & $\begin{array}{l}\text { Mortality in children } \\
\text { younger than } 5 \text { years in the } \\
2015-2018 \text { period }\end{array}$ & $\begin{array}{l}\text { Number of patients with } \\
\text { heart disease cared for in } \\
\text { the 2015-2018 period }\end{array}$ & $\begin{array}{l}\text { Human and material resources each hospital has for } \\
\text { the care of these patients }\end{array}$ \\
\hline $\begin{array}{l}\text { Tertiary care } \\
\text { hospital }\end{array}$ & Not reported & 37 patients & $\begin{array}{l}\text { Has professional staff trained for medical care at the } \\
\text { pediatric cardiology department }\end{array}$ \\
\hline $\begin{array}{l}\text { Secondary } \\
\text { care hospital }\end{array}$ & 1 case & Not reported & $\begin{array}{l}\text { Pediatric cardiologist, pediatric hemodynamics } \\
\text { specialist, pediatric cardiovascular surgeon, } \\
\text { echocardiography team, pediatric anesthesiologist, } \\
\text { three pediatric intensivists, non-portable } \\
\text { echocardiograph }\end{array}$ \\
\hline
\end{tabular}

\section{Results}

The results are shown in two sections, the first one according to data provided by the National Transparency Platform with file numbers 04151419, 04151319, 04151619, and 04151519, and the second based on data from the review of the pediatric cardiology and pediatric cardiovascular surgery departments databases in the participating hospitals.

Below, the data reported by the National Transparency Platform with the above-mentioned file numbers and with the different requested points, are shown and listed in table 1.

a) Heart disease-related mortality in children younger than 5 years in the 2015-2018 period:

1. Tertiary care hospital: mortality is not recorded.

2. Secondary care hospital: 1 patient.

b) Patients younger than 5 years with heart disease treated in the 2015-2018 period:

1. Tertiary care hospital: 37 patients.

2. Secondary care hospital: not recorded.

c) Main treated conditions:

1. Tertiary care hospital: mitral and aortic valve disease, specific, and nonspecific congenital heart malformations.

2. Secondary care hospital: atrial septal defect, ventricular septal defect, patent ductus arteriosus, arrhythmias, Kawasaki's disease, and pulmonary hypertension.

d) Human and material resources available at each hospital to serve these patients.

1. Tertiary care hospital: professional staff available and trained to provide medical care at the pediatric cardiology department.

2. Secondary care hospital: one pediatric cardiologist, one pediatric hemodynamics specialist, one pediatric cardiovascular surgeon, one pediatric anesthesiologist, and three pediatric intensivists. One non-portable echocardiogram.
The data obtained according to the review of files at the pediatric cardiology and pediatric cardiovascular surgery departments of the participating hospitals are the following:

a) Secondary care hospital: in the section on available resources for the care of these patients, no differences were identified with regard to data reported by the National Transparency Platform.

As for the number of patients with heart disease in the 2015-2018 period, a total of 624 patients with any type of heart disease was detected, out of which $92.1 \%$ $(n=575)$ corresponds to non-critical heart diseases, and the rest $(n=49)$, to critical disorders. The main population served corresponds to patients in the neonatal period, with $56.81 \%$ of identified heart diseases corresponding to patent ductus arteriosus, which, in case of requiring surgical closure, it is performed by the pediatric surgery department.

This hospital, despite having most of the human resources for the care of patients with CHD, lacks the material to practice any type of intervention, and patients who need any procedure must therefore be referred to another institution; $50.2 \%$ of the population $(n=313)$ had to be referred to a tertiary care center; however, only $25.5 \%$ of these patients could be transferred to tertiary care facilities; it should be noted that many of these patients were referred by outpatient services to another hospital. Regarding the 49 cases with critical heart diseases, 39 could not be transferred $(79.59 \%)$ and of the 10 cases that were transferred, only two were received in a hospital of the Ministry of Health (for the rest, the families managed to have access to some type of social security coverage).

As regard mortality, an overall mortality of $12 \%$ of the population was identified; it should be noted that all 39 patients who suffered from some type of critical heart disease and who were not transferred to another unit 
Table 2. Data obtained from medical records of the cardiology department of the secondary care hospital of the Jalisco Ministry of Health

\begin{tabular}{|l|l|l|l|}
\hline Hospital & $\begin{array}{l}\text { Heart disease-related mortality in } \\
\text { children younger than } \mathbf{5} \text { years in the } \\
\mathbf{2 0 1 5 - 2 0 1 8} \text { period }\end{array}$ & $\begin{array}{l}\text { Number of patients attended to for } \\
\text { heart diseases in the 2015-2018 period }\end{array}$ & $\begin{array}{l}\text { Available human and material } \\
\text { resources }\end{array}$ \\
\hline $\begin{array}{l}\text { Secondary } \\
\text { care hospital }\end{array}$ & $\begin{array}{l}\text { Overall, 12\% } \\
\text { Critical heart diseases, } 79.5 \% \\
\text { Non-critical heart diseases, } 6 \%\end{array}$ & $\begin{array}{l}624 \text { patients } \\
\text { Critical heart diseases, } 49(7.8 \%) \\
\text { Non critical heart diseases }(92.2 \%)\end{array}$ & $\begin{array}{l}\text { Pediatric cardiologist, pediatric } \\
\text { hemodynamics specialist, } \\
\text { cardiovascular surgeon, pediatric } \\
\text { anesthetist and two pediatric } \\
\text { intensivists } \\
\text { Portable echocardiograph }\end{array}$ \\
& & &
\end{tabular}

Table 3. Data obtained from the review of records of the tertiary care hospital of the Jalisco Ministry of Health

\begin{tabular}{|c|c|c|c|}
\hline Hospital & $\begin{array}{l}\text { Heart disease-related mortality } \\
\text { in children younger than } 5 \text { years } \\
\text { in the } 2015-2018 \text { period }\end{array}$ & $\begin{array}{l}\text { Number of patients } \\
\text { attended to for heart diseases in } \\
\text { the } 2015-2018 \text { period }\end{array}$ & Available human and material resources \\
\hline $\begin{array}{l}\text { Tertiary care } \\
\text { hospital }\end{array}$ & Overall, $20.4 \%$ & 289 surgeries & $\begin{array}{l}\text { Two pediatric cardiologists, one pediatric } \\
\text { cardiovascular surgeon, cardiopulmonary } \\
\text { bypass pump, pediatric intensivists, two } \\
\text { perfusionists, pediatric anesthetist, one } \\
\text { portable echocardiograph }\end{array}$ \\
\hline
\end{tabular}

passed away (the rest of mortality corresponds to patent ductus arteriosus; Table 2).

b) Tertiary care hospital

Based on the data obtained in the review of records of the pediatric cardiovascular surgery department, it was found that, between 2015 and 2018, a total of 289 operations were practiced; the heart conditions that were treated were patent ductus arteriosus in $36.5 \%$ ( $n=105)$, ventricular septal defect in $25 \%(n=72)$, atrial septal defect in $16 \%(n=45)$, aortic coarctation in $14 \%$ $(n=41)$, tetralogy of Fallot in $6 \%(n=19)$, double outlet right ventricle in $1 \%(n=3)$, and tricuspid atresia in $1.38 \%(n=4)$.

Reported mortality was 59 patients (20.4\%), of which $80 \%(n=47)$ died in the pediatric intensive care unit.

Available resources include two pediatric cardiologists, one pediatric cardiovascular surgeon, pediatric intensivists, perfusionists, and cardiopulmonary bypass pump (Table 3).

\section{Discussion}

Many cardiovascular diseases cannot be prevented and evolve independently in a subsequent stage or age. CHDs occur in nearly 1/1000 births and have an heterogeneous component that influences on disease incidence and evolution. Even in optimal conditions, i.e., eradicated poverty, practice of exercise, healthy nutrition, and no drinking or smoking, cardiovascular disease would still occur to some degree ${ }^{8}$. The incidence of severe CHD approaches 2.5-3/1000 births. CHD moderate forms occur in almost $3 / 1000$ births, but other 13/1000 births develop mild CHD that ultimately will require cardiologic care ${ }^{3}$. In this country, there are no data that guide about the actual prevalence of $\mathrm{CHD}$; however, a theoretical average can be considered, derived from global information: $8 / 1000$ live births. When relating this figure to the annual birth rate in Mexico $(2500,000)$, it can be inferred that around 18,000 21,000 children are born with some type of cardiac malformation each year ${ }^{5}$. In the year 2017, in the state of Jalisco, 151,950 children were born ${ }^{6}$; if the above-mentioned prevalence rate is taken into account, around 1216 children were born in Jalisco in 2017 with some CHD, of which nearly the half will develop clinically significant heart disease ${ }^{9}$ and will require some form of intervention; this means that, in Jalisco, only in 2017, a little more than 600 children required urgent cardiovascular care, but in a secondary care hospital offering any kind of treatment is not possible, and that is the number of patients that was assessed in the 3 years covered by the study and, even worse, half of the required interventions were carried out at the tertiary care hospital within the 3 years of the study in 
comparison with the number it was necessary to care for in a single year, i.e., less than one-third of the population had access to cardiologic treatment and in most cases it was suboptimal.

In historical terms, most patients with $\mathrm{CHD}$ die at early stages of childhood. However, in the past four decades, extraordinary advances have been achieved in this field. Actually, the latest population prevalence studies indicate that now the number of adults is almost the same as the number of children with serious defects ${ }^{10}$. In high-income countries, CHD mortality has significantly decreased, but not in those of medium or low income. The mortality difference between industrialized countries and the third world it is notorious, from $3 \%$ to $7 \%$ and up to $20 \%$, respectively. However, $\mathrm{CHD}$ mortality is likely to be underestimated in third-world countries due to limited access to diagnosis, and the vast majority of studies only report cases of patients from tertiary care centers ${ }^{5}$, as in the case of Jalisco. The mortality herein recorded is extremely high; at the secondary care hospital, $80 \%$ of patients with critical heart disease die without being able to undergo any kind of palliative and much less corrective procedure; in addition, up to $6 \%$ mortality is recorded in non-critical heart disease, which corresponds to patent ducts arteriosus in neonatal patients. At the tertiary care hospital, surgical mortality is slightly higher than $20 \%$. However, data on mortality in CHD can often be interpreted within the context of medical and surgical care availability; there are hospital centers in Mexico City that register a mortality of $2.9 \%$ for $\mathrm{CHD}^{11}$. Why is there so much difference between one state and another? The high rate of mortality for $\mathrm{CHD}$ in Jalisco is multifactorial, and differences with regard to Mexico City's hospitals could perhaps be due to (a) lack of access to specialized centers and late referrals, (b) high costs for the care of these patients in a bureaucratic and underfunded health system, (c) lack of multidisciplinary and specialized units for patients with CHD, and (d) lack of doctors and nurses trained for the care of these patients ${ }^{11}$.

Regarding hospital resources, one of the most important data that should be assessed in these patients is the scope of treatment and the effect on the results for CHD; medical and surgical care of CHD requires many resources. Actually, establishing an accurate diagnosis is often complex, and to do it, expensive diagnostic modalities are needed, in addition to highly-trained specialist doctors. CHD surgical treatment also consumes considerable resources, complex infrastructure and equipment, and highly certified professionals. Obviously, it is highly expensive ${ }^{7}$. As for infrastructure, according to the proposal by Calderón et al. of $2010^{5}$, based on recommendations established by the CHD Committee of the European Association of Cardiothoracic Surgeons, and in relation to a Mexican population calculated at 103 million inhabitants, around 25 cardiac surgery centers are required for congenital heart conditions. On the other hand, in Mexico, nearly 2 million children are born each year. If the American Pediatrics Academy criteria are considered, i.e., one medical-surgical center per 30,000 live births, hospital requirements would be 66 heart surgery units. Jalisco has 8.2 million inhabitants and, therefore, two surgical cardiovascular centers are required, according to the European Association of Cardiothoracic Surgeons CHD Committee guidelines, and five cardiovascular centers according to the American Academy of Pediatrics guidelines. However, in this state, there are only two centers that perform operations in congenital heart defects, one from the social security system and a tertiary care hospital of the Ministry of Health that serves the population without social security and that often is the most vulnerable. Based on the protocols of the European Association of Cardiothoracic Surgeons Committee of CHDs, for a center that practices cardiac interventions to be considered profitable, the following is required ${ }^{12}$ :

1. The number operated per year should be at least 250 and more than 100 cases per year in newborns and children younger than 1 year.

2. Each surgeon should carry out at least three operations per week and 126/year.

3 . In the case of units with lower volume $(<250$ patients a year), they can be considered as functional hospitals if the results are similar to those of centers that serve a higher volume.

The number of patients operated at the tertiary care hospital is 289 in 3 years, i.e., said hospital is not profitable; however, it cannot reach that goal because it lacks a multidisciplinary team (pediatric cardiologists, pediatric cardiovascular surgeons, pediatric cardiovascular intensivists, cardiovascular intensive care nurses, perfusionists, pediatric cardiovascular anesthesiologist, social worker, psychology department involvements, etc.) and, since it is a public hospital, it has notable financial limitations and a highly bureaucratic organization that hinders establishing high-quality control systems. Paradoxically, the secondary care hospital has most of the necessary human resources for the care of patients with CHD and yet, however, it lacks support of the government for obtaining material resources for the care of these patients. 
Another important point that should be taken into account, regarding the high rates of mortality of patients with $\mathrm{CHD}$ in the state of Jalisco, is the inadequate reference system, since in many cases it is not possible for patients to be transferred to a unit that practices life-saving procedures, regardless of whether it is a critical heart disease that mandates immediate attention. This is a consequence of patient volume and insufficient resources in public hospitals, which evidently contributes to increased mortality. As previously mentioned, multidisciplinary teams are required for the care of patients with congenital heart conditions to obtain better results; however, many times patients receive primary care from doctors who are poorly trained in pediatric cardiology and who often refer and detect patients at a very late phase. To sum up, many of these deaths occur due to poor quality of care by inefficient hospital resources and adverse social circumstances.

Finally, the large discrepancy between the information obtained through the transparency system and hospitals' real information should be noted; it is therefore highly important for the Jalisco state statistics systems to be improved to record real data of the patients cared for in this state.

Despite the fact that cardiologic care teams (pediatric cardiologists, pediatric cardiovascular surgeons, pediatric intensivists, nurses, and perfusionists) who serve in Jalisco hospitals try to provide timely and quality care to these patients, this is not enough due significant limitations; there is still much to do to ensure that all children born in the state with heart abnormalities receive appropriate and timely medical and surgical care.

\section{Conclusion}

CHDs in the state of Jalisco are an important cause of mortality, with a high incidence and downright limited resolution capacity, since health services in the Jalisco state for the care of these patients are significantly insufficient and inadequate.

According to article four of the Mexican Constitution, "Boys and girls have the right to satisfaction of their needs for food, health, education, and healthy recreation for their comprehensive development. The state will grant assistance to individuals to contribute to the fulfillment of the rights of childhood". Health is a basic human right. All children who are born with CHD deserve to receive treatment and have access to interventions capable to save their life and these should not be reserved for those born in specific areas of the country. No child with CHD should die due to a lack of resources.

To overcome this great disparity in access to cardiac surgery services, it is essential for the health system to be strengthened for the care of these patients.

\section{Funding}

None.

\section{Conflicts of interest}

The authors declare that they have no conflicts of interest.

\section{Ethical disclosure}

Protection of people and animals. The authors declare that no experiments on humans or animals were performed for this investigation.

Confidentiality of data. The authors declare that they have followed the protocols of their work center on the publication of patient data.

Right to privacy and informed consent. The authors declare that no patient data appear in this article.

\section{References}

1. Mitchell SC, Korones SB, Berendes W. Congenital heart disease in 56,109 births incidence and natural history. Circulation 1971;43:323-332.

2. Khairy P, lonescu-Ittu R, Mackie AS, Abrahamowicz M, Pilote L, Marelli AJ. Changing mortality in congenital heart disease. J Am Coll Cardiol 2010;56(14):1149-1157.

3. Hoffman JI, Kaplan S. The incidence of congenital heart disease. J Am Coll Cardiol 2002;39(12):1890-900.

4. Marelli Aj, Mackie AS, lonescu-Ittu R, Rahme E, Pilote L. Congenital heart disease in the general population: changing prevalence and age distribution. Circulation 2007;115(2):163-172.

5. Calderón-Colmenero J, Cervantes-Salazar JL, Curi-Curi PJ, Ramírez- Marroquín S. Problemática de las cardiopatías congénitas en México. Propuesta de regionalización. Arch Cardiol Mex 2010;80(2):133-140.

6. INEGI, Nacimientos registrados, por entidad federativa período y sexo 2015. https://www.inegi.org.mx/programas/natalidad/default.html\#Tabulados, revisado 03/07/2019

7. Bernier PL, Stefanescu A, Samoukovic G, Tchervenkov Cl. The challenge of congenital heart disease worldwide: epidemiologic and demographic facts. Semin Thorac Cardiovasc Surg Pediatr Card Surg Annu 2010;13(1):26-34.

8. Vervooot $D$. The neglected component of cardiovascular care. Glob Heart 2019:18:1-3.

9. Gelb BD. Genetic basis of congenital heart disease. Curr Opin Cardiol 2004;19(2):110-5.

10. Khairy P, lonescu-Ittu R, Mackie AS, Abrahamowicz M, Pilote L, MareIli AJ. Changing mortality in congenital heart disease. J Am Coll Cardiol 2010;56(14):1149-57.

11. Palacios-Macedo A, Mery CM, Cabrera AG, Basteros $P$, Tamariz-Cruz $O$, Diliz-Nava $\mathrm{H}$, et al. A novel private-public hybrid model for treatment of congenital heart disease in Mexico. World J Pediatr Congenit Heart Surg 201910(2):206-213.

12. Daenen W, Lacourt-Gayet $F$, Aberg T. Optimal structure of a congenital heart surgery department in Europe by EACTS congenital heart disease committee. Eur J Cardiothorac Surg 2003;24(3):334-51. 